\title{
Community Response to Settlement Relocation After Liquefaction in Petobo Village
}

\author{
Elly Kustiana, Iwan alim saputra, Amalia novarita \\ Universitas Tadulako \\ ellykustiana9@gmail.com
}

\section{Article History \\ accepted 31/08/2020}

\begin{abstract}
The liquefaction disaster caused loss of compact settlements in Petobo, the attention of the government to relocate community settlements to permanent residences. The purpose of this study was to knowing the response community of relocated settlement post liquefaction disaster in petobo. This study of type a qualitative description for purposive sampling. The general results analysis studies that 25 (83,33\%) to knowing the response community and 30 (100\%) the community response agree with for plan the relocated settlement's post liquefaction disaster in Petobo, Palu City. For 28 (98,33 \%) the community response disagrees with the government policy due to move the settlements another place. Generally, the community hope if the relocated settlements to do as soon as possible and still in petobo. Disagree process due too the community will not leave from petobo because they are authentic community in petobo.
\end{abstract}

Keywords: Respond, Relocated, Disaster, Liquefaction

\begin{abstract}
Abstrak
Bencana likuifaksi menyebabkan hilangnya permukiman padat Kelurahan Petobo, hal ini memunculkan perhatian bagi pihak pemerintah untuk merelokasi permukiman masyarakat ke hunian tetap. Penelitian ini bertujuan untuk mengetahui respon masyarakat terhadap relokasi permukiman pasca bencana likuifaksi di Kelurahan Petobo. Jenis penelitian ini adalah deskriptif kualitatif dengan pengambilan sampel purposive. Hasil penelitian menunjukan hasil analisis yang dapat disimpulkan bahwa pada umumnya, 25 (83,33 \%) responden masyarakat mengetahui dan $30(100 \%)$ responden masyarakat setuju dengan adanya rencana relokasi permukiman pasca bencana likuifaksi di Kelurahan Petobo Kecamatan Palu Selatan. namun, $28(98,33 \%)$ responden masyarakat menolak dan tidak setuju dengan kebijakan pemerintah yang akan memindahkan permukiman ke kelurahan lain. Umumnya masyarakat tetap berharap jika relokasi permukiman dapat dilaksanakan secepatnya dan tetap dilaksanakan di wilayah Kelurahan Petobo. Penolakan dilatarbelakangi oleh berbagai alasan diantaranya masyarakat tidak ingin meninggalkan Kelurahan Petobo karena mereka adalah penduduk asli yang sudah lama mendiami wilayah Petobo.
\end{abstract}

Kata kunci: Respon, Relokasi, Bencana, Liquifaksi]

Social, Humanities, and Education Studies (SHEs): Conference Series

p-ISSN 2620-9284

https://jurnal.uns.ac.id/shes e-ISSN 2620-9292 


\section{PENDAHULUAN}

Sulawesi Tengah dengan Ibu Kota Palu berada pada kawasan dataran lembah Palu dan Teluk Palu. Kota Palu memiliki sejarah Panjang tentang kebencanaan. Salah satu bencana yang terjadi di Kota Palu adalah gempa bumi yang diakibatkan oleh pergeseran aktif sesar Palu Koro, berdasarkan geologinya daerah Palu dan sekitarnya didominasi oleh endapan kuarter yang terdiri dari endapan fluvial dan alluvium. Kondisi alam tersebut yang mempengaruhi timbulnya potensi yang dapat merugikan diantaranya adalah potensi terjadinya bencana likuifaksi (Risna Widyaningrum, 2012). Bencana Liquifaksi termasuk bencana yang dianggap baru oleh masyarakat Palu khususnya oleh masyarakat petobo. Pada tanggal 28 September 2018 kota palu diguncang gempa bumi dengan kekuatan 7,4 SR memicu terjadinya bencana Liquifaksi di beberapa wilayah di Kota Palu, diantaranya Petobo, Balaroa, dan Jono Oge. Fenomena Liquifaksi ini banyak merugikan masyarakat secara fisik dan sangat krusial baik dari segi infrastruktur, sarana publik maupun hilangnya permukiman warga setempat. Hilangnya pemukiman padat warga di daerah Petobo, menyebabkan masyarakat tidak lagi memiliki tempat tinggal untuk dihuni. Berdasarkan jumlah data rekapitulasi kondisi bangunan akibat likuifaksi di Kelurahan Petobo rusak berat sebanyak 1.203 unit, rusak sedang 376 unit, rusak ringan 211 unit, dan bangunan hilang 1.230 unit (BPBD Kota Palu, 2018). Hingga kini masyarakat Petobo untuk sementara waktu hanya tinggal di hunian sementara dengan kondisi hunian yang sangat keterbatasan dari segi luas hunian dan sarana prasarana yang ada, berdasarkan rencana yang akan dilaksanakan oleh pemerintah bahwasannya permukiman masyarakat yang berada di area bencana Likuifaksi bagian Kelurahan Petobo akan direlokasi ke tempat wilayah yang aman dan tidak beresiko terjadinya bencana. Relokasi merupakan suatu tindakan untuk menata ulang pemukiman di sekitar wilayah rawan bencana yang bertujuan meminimalisir korban apabila terulang kembali bencana di kemudian hari. Relokasi didefinisikan sebagai proses dimana perumahan, aset, dan infrastruktur publik komunitas dibangun kembali di lokasi lain.(Rachmawan, 2019)

Upaya rehabilitasi pemerintah untuk bencana di Kota Palu dan sekitarnya dilihat dari berbagai aspek masih mengalami kendala. Salah satu kendala yang cukup besar adalah adanya kebijakan relokasi permukiman warga, khususnya di Petobo. Persetujuan dari masyarakat lokal, harga tanah, pembebasan tanah, bagaimana merencanakan penggunaan dan pemanfaatan tanahnya serta beberapa hal terkait pembangunan rumah warga yang direlokasi (Bronen \& Chaphin 2013) menjadi beberapa hal penting dalam upaya relokasi tersebut. Aspek lain yang mempengaruhi keberhasilan kegiatan rekonstruksi, relokasi ataupun rehabilitasi adalah pendanaan (Westi Utami, dkk : 2018) dan budaya. Keberhasilan pemerintah dalam merelokasi pemukiman warga menjadi tidak mudah dilakukan karena harus menyelaraskan presepsi dan preferensi warga dalam bermukim. Pro dan kontra masyarakat banyak ditemui dalam kebijakan relokasi pasca bencana tersebut (Stenfri Loy Pandia; dkk. 2016). Faktor yang terkait adanya perbedaan respon tersebut antara lain proses penyebaran informasi, komunikasi, serta keterlibatan masyarakat dalam proses perencanaan, tingkat pendidikan, hubungan sosial masyarakat yang terjalin, serta cara menyampaikan aspirasi kepada pemerintah (Fanni Harliani, 2014). Respon masyarakat terdampak terhadap kebijakan relokasi pemukiman menjadi penting, selain dari aspek fisik lahan yang telah ditentukan oleh pemerintah. Hal ini terkait dengan pengembangan wilayah di lokasi hunian baru pasca bencana.

Adapun rumusan masalah pada penelitian ini yaitu bagimana pengetahuan, sikap, dan harapan masyarakat terhadap kebijakan relokasi di salah satu daerah terdampak Likuifaksi yaitu Kelurahan Petobo. Serta respon masyarakat terhadap kebijakan relokasi permukiman terdampak bencana menjadi tujuan dari penelitian ini dapat diuraikan secara rinci, mengidentifikasi pengetahuan, sikap, dan harapan masyarakat 
terhadap kebijakan relokasi di salah satu daerah terdampak Likuifaksi yaitu Kelurahan Petobo.

\section{METODE}

Penelitian ini diuraikan secara deskriptif dengan menggambarkan fenomena realitas sosial masyarakat terdampak bencana (Bungin, 2011). Penentuan sampel pada penelitian ini menggunakan purposive random sampling. Data diambil dari subjek penelitian (responden) melalui wawancara yang kemudian dianalisis secara kualitatif. Responden ditentukan secara purposive yang diyakini dapat mewakili karakter populasi (Sabari Yunus, 2010). Subyek penelitian adalah masyarakat terdampak bencana likuifaksi Kelurahan Petobo yang berada di hunian sementara sebagai responden. Kriteria yang digunakan dalam menentukan subyek pada penelitian ini yaitu kepala keluarga laki-laki yang berusia $>40$ tahun yang memiliki istri dan anak sebagai responden. Kriteria didasarkan pada asumsi bahwa segala sesuatu keputusan akan diambil oleh orang yang paling berpengaruh dalam keluarga yaitu kepala keluarga. Hasil penelusuran masyarakat terdampak terdapat 30 orang KK yang memenuhi kriteria di lokasi penelitian (BPBD Kota Palu, 2018) dan dapat dijadikan responden.

Penelitian menggunakan beberapa teknik diantaranya observasi, wawancara, dokumentasi sedangkan instrumen pada penelitian ini menggunakan skala Guttman agar mendapatkan jawaban yang tegas (konsisten) terhadap suatu permasalahan yang ditanyakan. Data yang dihasilkan kemudian disajikan secara sederhana dengan persentase dan dianalisis secara deskriptif kualitatif.

\section{HASIL DAN PEMBAHASAN}

Kelurahan Petobo secara administratif terletak di wilayah Kecamatan Palu Selatan, Kota Palu Sulawesi Tengah. Kelurahan Petobo memiliki luas wilayah 10,40 $\mathrm{Km}^{2} / 1.040 \mathrm{Ha}$, dan termasuk kelurahan yang terluas di Kota Palu. Kelurahan Petobo salah satu wilayah yang teridentifikasi sebagai daerah potensi bencana liquifaksi, bencana ini menyebabkan wilayah Petobo mengalami kerusakan infrastruktur seperti hilangnya pemukiman masyarakat dan tidak layak untuk ditempati kembali. Oleh karena itu untuk mengantisipasi korban bencana liquifaksi Pemerintah memberikan kebijakan berupa bantuan hunian sementara kepada masyarakat yang terdampak bencana liquifaksi di Kelurahan Petobo Kota Palu. Saat ini masyarakat yang kehilangan tempat tinggal hanya bisa menempati hunian sementara di Petobo. Data yang diperoleh menunjukan bahwa jumlah penduduk $\leq 2.006$ jiwa dengan jumlah $\leq 869$ kepala keluarga yang tinggal disaat ini tinggal di hunian sementara Petobo (Sumber : Monografi Kelurahan Petobo Tahun 2019).

Responden pada penelitian ini adalah masyarakat yang saat ini tinggal di hunian sementara Kelurahan Petobo, yang menjadi korban akibat adanya bencana likuifaksi. Responden pada penelitian ini adalah kepala keluarga berjenis kelamin laki-laki yang berusia $>40$ tahun, jumlah responden pada penelitian ini berjumlah $30 \mathrm{KK}$. Karakteristik responden dapat dilihat pada tabel berikut 
Tabel 1. Tingkat Pendidikan Responden

\begin{tabular}{ccc}
\hline Tingkat pendidikan & Frekuensi & Persentase (\%) \\
\hline (1) & $\mathbf{( 2 )}$ & $(\mathbf{3})$ \\
\hline Tidak Tamat & - & - \\
SD & 10 & 30,33 \\
SMP & 11 & 36,66 \\
SMA & 8 & 26,66 \\
Diploma & - & - \\
Sarjana (PT) & 1 & 33,3 \\
\hline Total & 30 & 100 \\
\hline \multicolumn{1}{c}{ Tabel 2. Jenis Pekerjaan } & Responden & \\
\hline Umur & Frekuensi & Persentase (\%) \\
\hline (1) & $\mathbf{( 2 )}$ & $\mathbf{( 3 )}$ \\
\hline Petani & 11 & 36,66 \\
Wiraswasta & 6 & 20 \\
Buruh Bangunan & 2 & 6,66 \\
Pensiunan & 2 & 6,66 \\
Pegawai Honorer & 1 & 3,33 \\
Sopir & 1 & 3,33 \\
Serabutan & 5 & 16,66 \\
Tukang Batu & 1 & 3,33 \\
Karyawan & 1 & 3,33 \\
\hline Total & 30 & 100
\end{tabular}

Sumber : Olah data primer 2019

Penduduk di wilayah Petobo secara umum bervariasi (tingkat dasar). Responden terpilih menggambarkan variasi tersebut, antara lain: rata-rata responden berpendidikan dasar sampai menengah. Diperjelas dari data yang menunjukkan tamat SD $(30,33 \%)$, SMP (36,66\%), SMA (26,66\%), Perguruan tinggi $(3,33 \%)$. Penduduk di wilayah Petobo secara umum tidak bervariasi. Responden terpilih menggambarkan hal tersebut, dengan rata-rata responden yang berprofesi sebagai petani $(36,66 \%)$ dan wiraswasta $(20 \%)$, lainnya terdiri dari buruh bangunan, tukang batu, pegawai/karyawan swasta, sopir dan serabutan, serta pensiunan.

Salah satu upaya pemerintah untuk melakukan pendekatan kepada masyarakat petobo yaitu sosialisasi tentang relokasi permukiman yang akan dicanangkan sebagai kebijakan pemerintah dalam tahapan pemulihan kondisi tempat tinggal. Sosialisasi dinerikan agar tidak menimbulkan kesalahpahaman dari masyarakat akibat ketidaktahuan masyarakat tentang apa, maksud dan bagaimana rencana relokasi. Program relokasi permukiman lebih baik apabila diikuti pengetahuan masyarakat agar rencana relokasi dapat dilaksanakan secara transparan dan diketahui semua pihak terkait. 
Tabel 3 Penilaian Responden Menurut Pengetahuan Masyarakat Terhadap Relokasi Permukiman

\begin{tabular}{cccc}
\hline No & Jawaban & Frekuensi & $\begin{array}{c}\text { Persentase } \\
(\%)\end{array}$ \\
\hline $\mathbf{1}$ (1) & $\mathbf{( 2 )}$ & $\mathbf{( 3 )}$ & $\mathbf{( 4 )}$ \\
1 & $\begin{array}{c}\text { Tidak } \\
\text { mengetahui }\end{array}$ & 6 & 20 \\
2 & Mengetahui & 24 & 80 \\
\hline \multicolumn{2}{c}{ Total } & $\mathbf{3 0}$ & $\mathbf{1 0 0}$ \\
\hline
\end{tabular}

Relokasi permukiman merupakan salah satu kebijakan pemerintah dalam tahapan pemulihan kondisi tempat tinggal. keberhasilan progam tersebut sangat ditentukan oleh pengetahuan dan pemahaman masyarakat terdampak tentang relokasi.

Hasil penelitian yang telah dilakukan di hunian sementara Petobo mengenai pengetahuan masyarakat terhadap relokasi permukiman menunjukan bahwa 24 (80\%) responden masyarakat di daerah penelitian (PETOBO) secara umum sangat mengetahui, program relokasi permukiman pasca bencana. Terbukti dari data tentang pengetahuan masyarakat Petobo yang sebagian besar mengetahui bahwa area permukiman terdampak bencana (likufaksi) termasuk zona rawan dan tidak dapat dihuni lagi. Sosialisasi yang intensif dari pihak pemerintah menjadi dasar pengetahuan masyarakat terdampak bencana.

Tabel 4 Penilaian Responden Menurut Sikap Masyarakat Terhadap Relokasi Permukiman

\begin{tabular}{cccc}
\hline No & Jawaban & Frekuensi & $\begin{array}{c}\text { Persentase } \\
(\%)\end{array}$ \\
\hline $\mathbf{1}(\mathbf{1})$ & $\mathbf{( 2 )}$ & $\mathbf{( 3 )}$ & $\mathbf{( 4 )}$ \\
1 & Tidak & - & - \\
2 & setuju & 30 & 100 \\
& Setuju & & \\
\hline & Total & $\mathbf{3 0}$ & $\mathbf{1 0 0}$ \\
\hline
\end{tabular}

Proses relokasi permukiman di daerah penelitian sepenuhnya disetujui \& didukung oleh masyarakat terdampak. Hal ini, relevan dengan pemahaman penduduk yang tergolong sangat mengetahui dengan kejadian bencana likuifaksi. Proses relokasi mengalami hambatan dengan lokasi yang telah ditetapkan pemerintah. Tiga (3) area yang ditetapkan untuk menjadi pemukiman baru, tidak sepenuhnya disepakati (disetujui) oleh penduduk Petobo. Secara umum, masyarakat tidak ingin meninggalkan Petobo. Beberapa alasan mendasar yang melatarbelakangi adalah (1) masyarakat merupakan penduduk asli yang sejak dulu mendiami wilayah Petobo. Mayarakat kawatir apabila meninggalkan Kelurahan Petobo maka wilayah Petobo juga akan hilang atau dikuasai pihak lain. Hal ini sejalan dengan pernyataan pejabat desa, bahwa lahan yang ada di bagian timur hunian sementara (Kelurahan Petobo) masih terkena sengketa dengan daerah Kabupaten Sigi. (2) masyarakat beranggapan bahwa jika masyarakat harus berpindah, proses adaptasi menjadi sulit, karena semua hal baru (salah satunya pengurusan administrasi untuk berdomisili sampai tetangga baru). 
Sikap kontra yang ditunjukkan oleh penduduk Petobo, bertolakbelakang dengan pengetahuan penduduk tentang relokasi. Pengetahuan penduduk tidak disertai dengan pemahaman tentang proses relokasi pemukiman

Hasil penelitian bahwasanya masyarakat berharap pada pelaksanaan relokasi permukiman sebanyak $30(100 \%)$ untuk dapat segera dilaksanakan. Proses pemindahan (relokasi) hendaknya tidak dipersulit (terutama dalam hal administrasi), Lokasi hunian tetap diharapkan aman dari bencana, agar permukiman yang baru dapat dihuni dengan layak dan nyaman oleh masyarakat. Relokasi permukiman yang akan di bangun oleh pemerintah diharapkan memiliki infrastruktur yang memadai dan bisa dimanfaatkan oleh masyarakat Hunian Tetap Petobo. Relokasi permukiman Ini merupakan program pemerintah Kota Palu untuk menanggulangi bencana.

\section{SIMPULAN}

Hasil penelitian dan pembahasan yang telah diuraikan sebelumnya, maka diambil kesimpulan sebagai berikut Masyarakat mengetahui informasi mengenai relokasi dari sosialisasi yang pemerintah berikan sebelum ada pembangunan hunian tetap. Responden masyarakat setuju dengan adanya rencana relokasi pasca bencana. Responden masyarakat sangat mengharapkan pemerintah agar segera mempercepat dan merealisasikan proses relokasi hunian tetap sesuai dengan keinginan masyarakat. Alasan masyarakat menolak usulan pemerintah karena masyarakat tidak ingin meninggalkan lokasi Petobo yang mana sebagian besar masyarakat merupakan penduduk asli, sehingga perlu ada pendekatan khusus.

Saran untuk pemerintah dapat memberikan penjelasan terkait kebijakan dan pertimbangan dalam melaksanakan tahapan relokasi bagi masyarakat wilayah Petobo. Pemerintah dan masyarakat wilayah perobo saling bersinergi dan berkomunikasii secara intensif dari pihak pemerintah menjadi dasar pengetahuan masyarakat terdampak bencana. Masyarakat harus dapat mendukung kebijakan pemerintah, dengan mempertimbangkan segala aspek yang mendukung kegiatan relokasi sehingga proses relokasi dapat dilaksanakan secepatnya. Masyarakat perlu meningkatkan pengetahuan mengenai bencana alam seperti gempa bumi, tsunami, likuifaksi dan bencana alam lainnya dan meningkatkan pengetahuan mengenai mitigasi bencana.

\section{DAFTAR PUSTAKA}

Ayuningtyas, Dian (2013). Respon masyarakat terhadap kebijakan Relokasi pada kawasan rawan bencana (KRB) (Studi kasus: Relokasi Desa Glagaharjo) Universitas Gadjah Mada : Yogyakarta

Bungin Burhan (2011). Penelitian Kualitatif (Komunikasi, Ekonomi, Kebijakan Publik dan IImu Sosial Lainnya). Prenada Media Group : Jakarta

BPBD Kota Palu. (2019). Rekapitulasi data Kondisi Bangunan Akibat Bencana Kota Palu

Bronen, R., Chaplin, FS (2013), Adaptive governance and institusional strategies for climate-induced community relocations in Alaska, Proceedings of the National Academy of Sciences, 110 (23), hlm. 9320-9325, Doi: 10.1073/pnas.1210508110

Harliani Fanni, (2014). Persepsi Masyarakat Kampung Cieunteung Kabupaten Bandung Tentang Rencana Relokasi Akibat Bencana Banjir. (Jurnal Perencanaan Wilayah Dan Kota Vol 25 No. 1 Hml 37-57 April 2014). Bandung : Sekolah arsitektur perencanaan pengembangan dan kebijakan ITB 
Pandia, Stenfri Loy. Dkk. (2016). Relokasi Permukiman Desa Suka Meriah Akibat Kejadian Erupsi Gunung Api Sinabung Kabupaten Karo. Jurnal Perencanaan Wilayah Dan Kota Vol 27 No.PP 137-150 Agustua 2016. Yogyakarta : Fakultas Geografi UGM

Rachmawan. DKK (2019). Potensi Pengadaan Tanah Berbasis Kebencanaan Di Kota Palu. Jurnal Tugas Agraria vol 2 no. 3 September 2019. Yogyakarta : Sekolah Tinggi Pertanahan Indonesia.

Utami, Westi. dkk (2019) Analisis Spasial Untuk Lokasi Relokasi Masyarakat Terdampak Tsunami Selat Banten Tahun 2018. Jurnal Agraria dan Pertanahan Vol. 5 No. 1 Mei 2019 no. 1, hlm. 112-128.

Widyaningrum, Risna. (2012) Penyelidikan Geologi Teknik Potensi Liquifaksi Daerah Palu, Provinsi Sulawesi Tengah. Badan Geologi : Bandung

Yunus, Hadi Sabari. 2010. Metodologi Penelitian Wilayah Kontemporer. Yogyakarta : PUSTAKA BELAJAR 